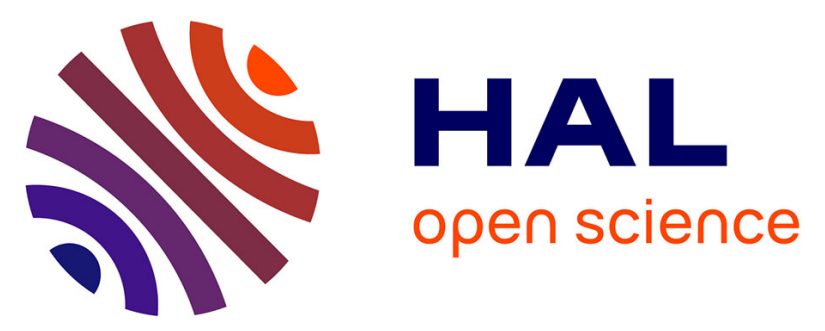

\title{
Analysis of Implementation of Care Coordination in a Multi-level Care Provider Organization: A Need for Systems Approaches
}

Guillaume Lamé, Tu Anh Duong, Marija Jankovic, Julie Stal-Le Cardinal, Oualid Jouini

\section{To cite this version:}

Guillaume Lamé, Tu Anh Duong, Marija Jankovic, Julie Stal-Le Cardinal, Oualid Jouini. Analysis of Implementation of Care Coordination in a Multi-level Care Provider Organization: A Need for Systems Approaches. International Conference on Complex Systems Design \& Management, CSD\&M 2015, Nov 2015, Paris, France. pp.107-118, 10.1007/978-3-319-26109-6_8 . hal-01233987

\section{HAL Id: hal-01233987}

https://hal-centralesupelec.archives-ouvertes.fr/hal-01233987

Submitted on 26 Nov 2015

HAL is a multi-disciplinary open access archive for the deposit and dissemination of scientific research documents, whether they are published or not. The documents may come from teaching and research institutions in France or abroad, or from public or private research centers.
L'archive ouverte pluridisciplinaire HAL, est destinée au dépôt et à la diffusion de documents scientifiques de niveau recherche, publiés ou non, émanant des établissements d'enseignement et de recherche français ou étrangers, des laboratoires publics ou privés. 


\title{
Analysis of Implementation of Care Coordination in a Multi-Level Care Provider Organization: a Need for Systems Approaches
}

\author{
Guillaume Lamé, Tu-Anh Duong, Marija Jankovic, Julie Stal-Le Cardinal, Oualid Jouini
}

\begin{abstract}
Better care coordination is a crucial objective to answer to the rising complexity of healthcare and the associated increase in costs. Process-based organizations is a widely recommended method for achieving this goal.

In this article an initiative of implementing a care process in a French public hospital group is analyzed. The procedure to design the care process is documented and the official care process is compared to the current situation in a hospital. This analysis shows how important local parameters are in such projects. The shortcomings of the approach are identified and propositions to overcome these issues are made.
\end{abstract}

\section{Introduction}

Health care systems around the world are under pressure. As life expectancy is increasing and chronic diseases are getting more frequent, demand is rising but national expenditure is not rising as fast [1]. Therefore there is a clear need for productivity increase. In France, hospitals have been identified as one of the sources of increase of global efficiency [2].

However, in the same time, care complexity is continuously increasing [3], and hospitals have longsince been identified as complex organizations [4]. In this ever-increasing complexity, sources of productivity need to be identified and efficiency losses need to be addressed.

To deal with this situation, organ-based silo organizations are no longer adequate and better care coordination should be attained [5]. Systems engineering approaches have been identified as a way forward [6], and as a part of this process-based organizations have been promoted to achieve better coordination. Consequently, hospitals have started to shift towards more process-oriented organizations by designing care processes. However, social scientists have shown that theoretical organizations and real-life events are not the same thing [7]. More particularly Nyssen [8] shows that real-time care coordination can be an "emergence-through-use" phenomenon. The intent of the designer of the management procedures and the behavior of the real system can be two very different things.

In this context, the objective is to achieve coordination by design in order to have more robust and predictable coordination mechanisms. How can this be achieved? To answer this question, an initiative from a French care provider is studied in this article. It is a top-down project aiming at the implementation of an integrated care process for cancer care. The coordination mechanism "as

Guillaume Lamé, Tu-Anh Duong, Marija Jankovic, Julie Stal-Le Cardinal, Oualid Jouini

Laboratoire Genie Industriel

Ecole Centrale Paris

Grande Voie des Vignes, 92290 Chatenay-Malabry, FRANCE

Guillaume.lame@ecp.fr 
Analysis of Implementation of Care Coordination in a Multi-Level Care Provider Organization: a Need for Systems Approaches

designed" is compared to the situation "as happening". Dates of main events are gathered from medical records to build a picture of the real current situation. This situation is confronted with the desired model.

Conclusions are drawn for the design of coordination-enabling systems and processes and the management of large complex organizational systems. Centralized and non-differentiated initiatives have poor chances of success. In this case, taking into account the diversity of cancer types and organizations is crucial.

\section{Context and literature review: care coordination}

\subsection{Care coordination}

Care coordination has been defined as "the deliberate organization of patient care activities between two or more participants (including the patient) involved in a patient's care to facilitate the appropriate delivery of health care services." [9] It includes resource management and is often achieved through information exchanges. To achieve this, process-oriented care organizations have been proposed as a solution [10]. Different approaches exist to implement process-based care organizations, which can be classified in two broad categories [11]: an "industrial" approach based on methods such as lean management, total quality management and business process reengineering [12]; and the "integrated care" stream, coming from the medical world, with a strong emphasis on evidence-based medicine [11, 13]. The organization studied here applied the "integrated care" approach, although evidence is limited on the efficiency of such a method (Vanhaecht shows that integrated care pathways improve some aspects of care coordination [13], but other researchers exhibit mixed results for clinical pathways initiatives [14, 15]).

\subsection{French context for cancer care coordination}

In France, cancer care coordination is organized as a multi-level system. Table 1 shows the different levels of care coordination at the national and regional levels and for the case of the care provider and the hospital at study.

This provider is a public grouping of university hospitals, hospitals and clinics. It has elaborated a cancer strategy to comply with national and regional directives and to maintain its leadership on cancer care and research. This strategy is informed by a cancer working group at the head of the organization. Expert centers are certified in the member-hospitals of the provider. This certification is an acknowledgement of their excellence for care and research.

Table 1. Levels of cancer care coordination in France

\begin{tabular}{|l|l|l|}
\hline \multicolumn{1}{|c|}{ Level } & \multicolumn{1}{c|}{ Actions and responsibilities } & \multicolumn{1}{c|}{ Figures } \\
\hline France & $\begin{array}{l}\text { Plan Cancer 2014-19: strategy and objectives } \\
\text { National Cancer Institute (INCa): recommendations and } \\
\text { certification }\end{array}$ & $\begin{array}{l}\text { 3 million patients } \\
355.000 \text { new cases / y } \\
148.000 \text { deaths / y }\end{array}$ \\
\hline $\begin{array}{l}\text { Regional } \\
\text { health }\end{array}$ & Transcription of national directives into regional policy & \\
\hline
\end{tabular}


Analysis of Implementation of Care Coordination in a Multi-Level Care Provider Organization: a Need for Systems Approaches

\begin{tabular}{|l|l|l|}
\hline agency & Audit & \\
\hline Provider & $\begin{array}{l}\text { Cancer working group } \\
37 \text { Expert Centers }\end{array}$ & $\begin{array}{l}30 \% \text { of region's cases } \\
83.500 \text { patients / year }\end{array}$ \\
\hline Hospital & $\begin{array}{l}3 \text { Expert Centers, } \\
1 \text { Cancer Coordination Center }\end{array}$ & \\
\hline
\end{tabular}

As part of its cancer strategy, the provider has launched an initiative to improve its organization for providing cancer care. This initiative is related to the "integrated care pathways" concept. A care process has been designed for implementation in all member hospitals, and indicators have been defined to manage this process.

In this study the objective is to analyze this project and contrast it with systems engineering perspectives. Indeed, previous studies have shown limited adherence to clinical pathways [16] and mixed results when comparing theoretical processes with real-life events $[7,8]$, which raises questions on the approach used.

Usually, systems engineering starts with the analysis of context, environment, shareholders and objectives. Then specifications are established for the system. Finally processes are designed [17]. This phase is top-down, from the system towards its elements. The design of the care process is documented and situation at the operational level, i.e. the "down" part of this top-down initiative, is analyzed to draw conclusions on the approach used.

\section{Methods}

First, a qualitative study is conducted to understand how the process for cancer care was designed. This analysis is performed by document analysis and a 45 minutes semi-directed interview with the head of the oncology department at the studied hospital, who was also a member of the process design project team.

Then data is analyzed for some patients in the hospital. Two cancer types are targeted: prostate cancer and pancreas cancer. This choice is made based on data-availability and number of patients treated at the hospital. For these two types of cancer, patient records are analyzed based on the following criteria:

- All patients treated for the first time between January and June 2014 and coded in a DiagnosisRelated Group of prostate cancer or pancreas cancer

- Both inpatient and outpatient treatment were considered

- Patients who have been treated for cancer in the 3 previous years are excluded

Data comes from three sources: the medical records management system, the appointment scheduling system, and the Diagnosis-Related-Group payment management system. Following information is gathered:

- Age, ID, cancer code

- Date and department of the first appointment, date of announcement consult 
Analysis of Implementation of Care Coordination in a Multi-Level Care Provider Organization: a Need for Systems Approaches

- Cancer characteristics: metastatic or not, diagnosis (with biopsy results) available at first consult or not, additional exams needed or not, first Gleason score measured for prostate cancer (Gleason score measures the aggressiveness of a tumor. The higher the Gleason score, the worse the prognosis.)

- Date of the first multidisciplinary meeting where the case was discussed

- Date of the biopsy and date of the biopsy report, dates and types of treatments

- Date of apparition of metastasis if relevant, date of decease if relevant

- Number of consults, number of hospital stays, departments involved in the care

As this was the first study of this type, information is extracted manually.

\section{Materials and results}

\subsection{Qualitative study: process design and implementation}

The analysis of the documents produced by the process design team and the interview with the oncology professor provide a good understanding of the care process that was designed and the way it was designed. The cancer care process itself is pictured in figure 1. It is structured in four phases: entrance in the system, diagnosis, treatment and "after-care". It specifies a set of guiding principles:

- Cancer announcement should be done in two steps: one for diagnosis announcement, and one for treatment announcement

- These two announcement steps should be two different consults

- Between these two consults, treatment should be discussed in a multidisciplinary meeting, with at least three different medical specialties (e.g. urologist, oncologist and radiotherapist)

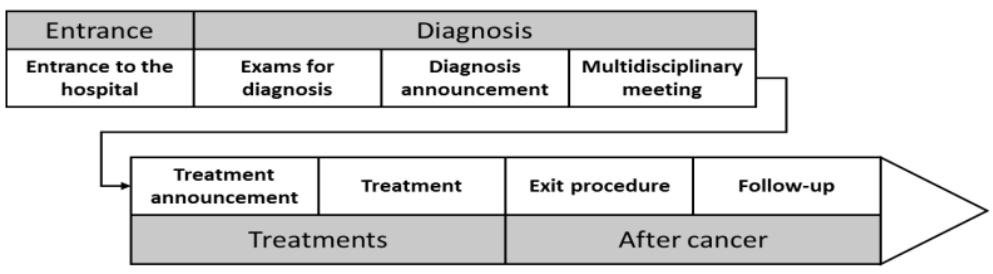

Fig. 1. Cancer care process

Six delay indicators are defined on this process. They are described in table 2.

Table 2. KPIs for the cancer care process

\begin{tabular}{|ccc|}
\hline$\#$ & From & To \\
\hline D1 & Scheduling of first appointment & First appointment \\
\hline D2 & First appointment & Multidisciplinary Meeting (MDM) \\
\hline D3 & First appointment & First treatment \\
\hline D4 & Date of biopsy & Biopsy report \\
\hline
\end{tabular}


Analysis of Implementation of Care Coordination in a Multi-Level Care Provider Organization: a Need for Systems Approaches

\begin{tabular}{|ccc|}
\hline D5 & Date of biopsy & Molecular biology report \\
\hline D6 & First treatment & Second treatment \\
\hline
\end{tabular}

This process is at a very high level. Figure 2 shows how it was designed.

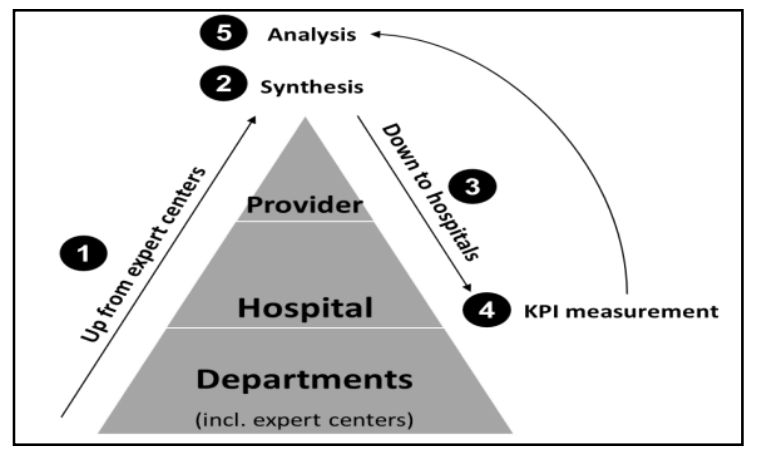

Fig. 2. Process design project

First, all expert centers were asked to draw a model of the care process for their specialty (e.g. urology cancers or blood cancers). No common formalism was provided, so various level of details were obtained. All the processes modelled by the expert centers were synthesized at the top-level of the provider in a mixed descriptive-prescriptive way which created the final care process of figure 1. KPIs were also defined at this stage. Then this process and its indicators were transmitted down to hospitals. A first KPI measurement was performed, where not all hospitals were able to measure all KPIs. The results were transmitted to the top level. Current thinking in the project group is on whether six KPIs is not too much and which KPIs could be deleted from the list.

Concerning the implementation of this process, in our hospital no resources have been allocated to this project. KPIs are not routinely computed. This will allow us to study the "real system" before implementation of this new procedure.

\subsection{Quantitative study: current situation in the hospital}

Two cancer types are studied: prostate and pancreas. For prostate cancer, 120 candidates are identified for inclusion. However, after the medical records have been analyzed, only 70 are included. For pancreas cancer, from 39 candidates 21 patients are included. Details are provided in table 3.

Table 3. Type of treatment received for prostate cancer care

\begin{tabular}{|c|c|c|c|c|}
\hline & \multicolumn{2}{|c|}{ Prostate } & \multicolumn{2}{c|}{ Pancreas } \\
\hline \hline Inclusion & \% of cand. & $\#$ & $\%$ of cand. & $\#$ \\
\hline Candidates for inclusion & $100 \%$ & 120 & $100 \%$ & 39 \\
\hline Patients included & $58 \%$ & 70 & $54 \%$ & 21 \\
\hline Wrong coding & $23 \%$ & 27 & $28 \%$ & 11 \\
\hline
\end{tabular}


Analysis of Implementation of Care Coordination in a Multi-Level Care Provider Organization: a Need for Systems Approaches

\begin{tabular}{|c|c|c|c|c|}
\hline Cancer in the previous 3 years & $26 \%$ & 31 & $38 \%$ & 15 \\
\hline Type of treatment received & $\%$ of incl. & \# & $\%$ of incl. & $\#$ \\
\hline Surgery & $91 \%$ & 64 & $10 \%$ & 2 \\
\hline Chemotherapy & $3 \%$ & 2 & $52 \%$ & 11 \\
\hline Radiotherapy & $4 \%$ & 3 & & 0 \\
\hline Hormonotherapy & $10 \%$ & 7 & & 0 \\
\hline 2 treatments & $9 \%$ & 6 & $10 \%$ & 2 \\
\hline Palliative care & $1 \%$ & 1 & $43 \%$ & 9 \\
\hline Average number of services & \multicolumn{2}{|c|}{$\#$} & \multicolumn{2}{|c|}{$\#$} \\
\hline & \multicolumn{2}{|c|}{1.5} & \multicolumn{2}{|c|}{3.3} \\
\hline
\end{tabular}

These two populations are very different. They don't use the same resources: on average, pancreas cancer patients transit through 3.3 departments, which is more than twice the number of departments for prostate cancer patients.

The types of treatment are also very different: mostly surgery for prostate cancer patients, chemotherapy and palliative care for pancreas cancer patients. Survival rates are completely different.

Finally, ways of entrance in the hospital also differ: most prostate cancer patients are detected through a prevention scheme, whereas there is no such protocol for pancreas cancer and most patients come for abdominal pains or other symptoms that need to be related to pancreas cancer.

As the number of included patients is low for pancreas cancer, only prostate cancer will be analyzed further. Two interesting comparisons can be made: with the provider-level process, and with national data. Table 4 shows delays computed for prostate cancer patients in the hospital (hosp.) and corresponding delays from a national investigation undertaken by the national cancer institute, INCa [18]. This investigation included both general hospitals and university hospitals, from the public and private sector, in 17 French regions (which cover almost $50 \%$ of the French population).

Table 4. Delays for prostate cancer care (MDM: multidisciplinary meeting)

\begin{tabular}{|c|c|c|c|c|}
\hline & & \multirow{2}{*}{$\begin{array}{c}\text { For all patients } \\
\text { Biopsy report to } \\
\text { MDM (days) }\end{array}$} & \multicolumn{2}{|c|}{ If surgery is performed } \\
\hline & & & $\begin{array}{l}\text { MDM to surgery } \\
\text { (days) }\end{array}$ & $\begin{array}{c}\text { Biopsy report to } \\
\text { surgery (days) }\end{array}$ \\
\hline Number & Hosp. & 70 & 63 & 63 \\
\hline
\end{tabular}


Analysis of Implementation of Care Coordination in a Multi-Level Care Provider Organization: a Need for Systems Approaches

\begin{tabular}{|c|c|c||c|c|}
\hline & INCa & 3050 & 1353 & 1350 \\
\hline \hline \multirow{2}{*}{ Data availability } & Hosp. & $96 \%$ & $44 \%$ & $45 \%$ \\
\cline { 2 - 5 } & INCa & $73 \%$ & $66 \%$ & $66 \%$ \\
\hline \hline \multirow{2}{*}{ Mean (SD) } & Hosp. & $10(49)$ & $109(92)$ & $122(102)$ \\
\cline { 2 - 5 } & INCa & $37(34)$ & $45(30)$ & $81(37)$ \\
\hline \multirow{2}{*}{\begin{tabular}{c} 
Medianterquartile) \\
\cline { 2 - 5 }
\end{tabular}} & Hosp. & $7(5-9)$ & $77(38-143)$ & $89(50-155)$ \\
\hline \hline \multirow{2}{*}{$\begin{array}{c}\text { Ratio of negative } \\
\text { results }\end{array}$} & Hosp. & $29(14-53)$ & $39(23-61)$ & $77(56-103)$ \\
\cline { 2 - 5 } & INCa & $\mathbf{3} \%$ & $\mathbf{5 5 \%}$ & $\mathbf{5 5 \%}$ \\
\hline
\end{tabular}

For mean and median computation, only positive values are included. They show that time from biopsy report to MDM is shorter in this hospital than nationwide. However, delays from MDM to surgery are longer in this hospital.

But the main comment that can be made on these results is on the ratio of negative results (the proportion of negative delays for all included patients). For the delay from MDM to surgery, this ratio is of $55 \%$ in this hospital, and $25 \%$ nationwide. It means that most patient get their surgery, and their case is discussed in the MDM only after that, when treatment has already been performed. This goes against the recommendations of the provider-level process. It also appears that surgery rates are much higher in this hospital ( $91 \%$ of patients) than nationwide ( $49 \%$ of cases in the INCa study).

Some additional treatment can be performed. For patients who had surgery, if no biopsy is performed at the hospital (which means that they already had biopsy results when they arrived), the delay between the first appointment and the treatment is significantly shorter (Student's t-test, unilateral, $p<0.001,38$ observations with biopsy at the hospital, 32 without). Also the relation between Gleason score and time to treatment can be analyzed. It shows that for Gleason scores 8, 9 and 10 (the most aggressive tumors), the delay between first appointment and treatment is significantly shorter than for Gleason scores 7 (Students t-test, unilateral, $p<0.01,51$ observations with Gleason 7, 12 with Gleason above 7). Therefore, if the diagnosis is clear from the beginning, time to treatment is faster, and the more serious the tumor the shorter the time to treatment. This is what would be expected.

\section{Discussion}

\subsection{Global project and local specificities}

Although patient record analysis is a long process (about a full week of work for one person to analyze the 159 records), a lot of data can be extracted. However, it is not clear how to make sense of this data. 
Analysis of Implementation of Care Coordination in a Multi-Level Care Provider Organization: a Need for Systems Approaches

A first point is surgery rates for prostate cancer. It is much higher in this hospital than nationwide. Nevertheless, the national study includes patients who were in the first steps of cancer and were put under surveillance. These "early" patients don't get hospitalized.

A second point is the rate of negative delays between MDM and treatment. One reaction could be to blame the hospital studied here: it is not following recommendations. However, this hospital has a well-known expertise for prostate surgery. It has some very specific equipment that make it a reference center for this type of intervention. Probably people come to this hospital for this reason: they choose surgery as a treatment with their private practitioner, and then go to this famous reference center. The surgeon only follows the patient's decision, for a surgery that has become almost a routine operation. These cases may also have been discussed in a MDM in another organization, after which the patient chose to be treated in this reference center.

Delays are another element to look at. Time to surgery can be longer or shorter (here it is difficult to say due to the high rate of negative delays), but it will depend on the population addressed by the hospital. The performed analysis shows that the more aggressive the tumor, the shorter the time to treatment. Delays depend on the severity of the patient's condition, which is understandable. Hospitals should therefore not be compared on this indicator. But even for one hospital, is this indicator supposed to rise or decrease? Actually, setting an objective could lead to counterproductive measures where the time from MDM to surgery is reduced on average but increased for more urgent patients.

All these elements (negative delays from MDM to surgery and high surgery rates due to hospital specialization and reputation, delays whose interpretation is uncertain) point to the specificity of each situation. Local contexts need to be taken into account to create relevant processes and indicators. Characteristics of this local context that need to be paid attention to include:

- Hospital specialization in one technique or another

- Hospital or physician reputation

- Population addressed

- Type of organization

Here, indicators could be associated to objectives, but these objectives would not reflect the complexity of the situation.

The comparison of prostate cancer and pancreas cancer is also instructive. It shows that treatments are very different for these two types of cancer, in the same organization: surgery is the main treatment for prostate cancer in the studied hospital, chemotherapy or palliative care for pancreas cancer.

The analysis performed and a discussion with practitioners showed that the uncertainty of the diagnosis is very different in these two cases. Pancreas cancer can go unnoticed for a while, and patients often come to the hospital with an advanced cancer. On the other hand, prostate cancer evolves more slowly, it has a nationwide detection scheme, and prostate surgery seems to have become a more routine operation in this hospital due to the large number of cases treated.

Therefore disease complexity should also be considered when establishing processes or indicators. Procedures can be more or less complex: standard, routine or non-routine [19]. Van der Geer et al. [20] have shown that when they are given the opportunity to develop their own performance 
Analysis of Implementation of Care Coordination in a Multi-Level Care Provider Organization: a Need for Systems Approaches

indicators, medical teams obtain different results depending on the uncertainty of the tasks and diseases. Therefore defining common indicators for these two types of cancer appears very challenging as the activities measured should not be the same: problem-solving for pancreas-cancer, treatment and outcomes for prostate cancer.

Vertical (across hierarchies), horizontal (across domain specialties) and longitudinal (along time) integration are needed [8] and should always take into consideration the complexity of local operations. Complexity can be described in three dimensions: diversity, multiplicity and interconnectedness [21]. In this case multiplicity has been considered but the importance of the diversity of patients, disease characteristics and organizations has been underestimated. Besides, interconnectedness between organizations characteristics and patient profiles has also been forgotten.

These considerations are at the heart of complex systems engineering. One of the conclusions is that systems engineering could help as it starts with the analysis of goals and context, then specifies the system before actually designing it. Here context analysis and goals of different shareholder have not been given enough attention which is why results are not as useful as hoped. When gathering information on current practices, specifications on process models were not given to expert centers, which is one of the reasons why the final unified process model was hard to design.

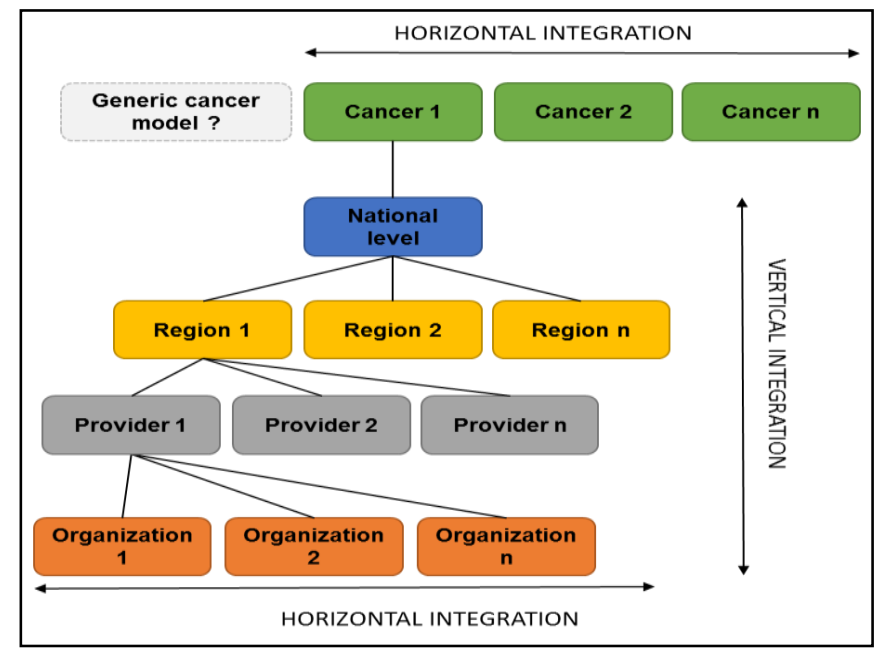

Fig. 3. Vertical and horizontal integration for cancer care in France: proposed framework

Figure 3 shows a proposition of integration scheme for cancer care in the provider studied here. It differs from the current architecture:

- Cancer types are differentiated at the top level, as they constitute different diseases with different care strategies and challenges. Horizontal integration must be achieved types if a generic metric for cancer care is desired.

- Comparisons between lower-level elements are possible at each level, but the metrics are not necessarily the same at each level.

This is related to the difference between tall organizational complexity and symmetric organizational complexity defined by Burton, De Sanctis and Obel [22]. Tall organizational complexities are fit for functional configurations in varied but predictable environments. Symmetric complexity is needed for turbulent (varied and hardly predictable) environments with matrix organizations: here, medical departments and care process across these departments. 
Analysis of Implementation of Care Coordination in a Multi-Level Care Provider Organization: a Need for Systems Approaches

\subsection{Strengths and limitations}

In this study, medical records for a 6-months period are analyzed. This analysis provides insights on how operations are currently performed, and how they are thought of at the top-level: the "bottomup view" of a "top-down" initiative.

However, the low number of patients for pancreas cancer did not allow much analysis on this population. Almost half of the candidate pancreas cancer patients could not be included. This relates to the more global issue of data access. This problem has already been identified in France [18] and other countries [23]. Data is hard to access as it is available in the form of free-text in medical records rather than in a database. It is also scattered between different information systems, and the reliability of data in these systems is not optimal as wrong coding is common.

\subsection{Future developments}

This study underlines the shortcomings of centralized, top-down approaches to the management and coordination of a complex system such as a group of hospitals. In this multi-level complex system, local situations are different and require differentiated approaches. Complex organizational systems theory and network analysis can be of great help.

The analysis of patient journeys for prostate cancer care and pancreas cancer care has shown that inside each cancer type different trajectories coexist. However, these trajectories are not readily available: patient data needs to be analyzed so that relevant patient groups can be identified. Data analysis methods such as Classification And Regression Tree analysis have already been used for operations research in healthcare [24]. They could be used to cluster patients for care coordination. For each of these groups of patients, an assessment of the coordination needs of the patients and the organization needs to be performed, so that appropriate resources can be allocated and other actions can be taken (reshape multidisciplinary teams, work on information systems...).

Finally, for such large systems as this health provider, "handmade" process mining is not enough and automated methods must be developed. However, hospital information systems are particularly divided and make this quite difficult.

\section{References}

1. OECD: Health at a glance 2013: OECD Indicators. Organisation for Economic Co-operation and Development, Paris (2013).

2. Cour des Comptes: La Sécurité sociale - Rapport sur l'application des lois de financement de la sécurité sociale. Cour des Comptes, Paris, France (2014).

3. Plsek, P.E., Greenhalgh, T.: The challenge of complexity in health care. BMJ. 323, 625-628 (2001).

4. Georgopoulos, B.S., Matejko, A.: The American General Hospital as a Complex Social System. Health Serv. Res. 2, 76112 (1967).

5. Glouberman, S., Mintzberg, H.: Managing the care of health and the cure of disease--Part II: Integration. Health Care Manage. Rev. 26, 70-84; discussion 87-89 (2001).

6. Reid, P.P., Grossman, J.H. eds: A Framework for a Systems Approach to Health Care Delivery. In: Building a Better Delivery System: A New Engineering/Health Care Partnership. National Academies Press, Washington, DC, États-Unis (2005).

7. Dupuy, F.: Lost in management: la vie quotidienne des entreprises au XXle siècle. Éditions du Seuil, Paris (2011).

8. Nyssen, A.-S.: Coordination in hospitals: organized or emergent process? Cogn. Technol. Work. 9, 149-154 (2007).

9. McDonald, K.M., Sundaram, V., Bravata, D.M., Lewis, R., Lin, N., Kraft, S.A., McKinnon, M., Paguntalan, H., Owens, D.K.: Closing the Quality Gap: A Critical Analysis of Quality Improvement Strategies (Vol. 7: Care Coordination). Agency for Healthcare Research and Quality (US), Rockville (MD) (2007).

10. Vera, A., Kuntz, L.: Process-based organization design and hospital efficiency. Health Care Manage. Rev. 32, 55-65 (2007). 
Analysis of Implementation of Care Coordination in a Multi-Level Care Provider Organization: a Need for Systems Approaches

11. Axelsson, R., Axelsson, S.B., Gustafsson, J., Seemann, J.: Organizing integrated care in a university hospital: application of a conceptual framework. Int. J. Integr. Care. 14, e019 (2014).

12. Ben-Tovim, D.I., Dougherty, M.L., O'Connell, T.J., McGrath, K.M.: Patient journeys: the process of clinical redesign. Med. J. Aust. 188, S14-17 (2008).

13. Vanhaecht, K.: The Impact of Clinical Pathways on the Organisation of Care Processes, (2007).

14. Panella, M., Marchisio, S., Di Stanislao, F.: Reducing clinical variations with clinical pathways: do pathways work? Int. J. Qual. Health Care. 15, 509-521 (2003).

15. Dy, S.M., Garg, P., Nyberg, D., Dawson, P.B., Pronovost, P.J., Morlock, L., Rubin, H., Wu, A.W.: Critical Pathway Effectiveness: Assessing the Impact of Patient, Hospital Care, and Pathway Characteristics Using Qualitative Comparative Analysis. Health Serv. Res. 40, 499-516 (2005).

16. Klundert, J. van de, Gorissen, P., Zeemering, S.: Measuring clinical pathway adherence. J. Biomed. Inform. 43, 861 $872(2010)$.

17. Walden, D.D., Roedler, G.J., Forsberg, K., Hamelin, R.D., Shortell, T.M., International Council on Systems Engineering eds: Systems engineering handbook: a guide for system life cycle processes and activities. John Wiley \& Sons Inc, Hoboken, New Jersey (2015).

18. INCa: Délais de prise en charge des quatre cancers les plus fréquents dans plusieurs régions de France en 2011 et 2012 : sein, poumon, côlon et prostate. Institut National du Cancer, Paris, France (2013).

19. Lillrank, P., Liukko, M.: Standard, routine and non-routine processes in health care. Int. J. Health Care Qual. Assur. Inc. Leadersh. Health Serv. 17, 39-46 (2004).

20. Van der Geer, E., van Tuijl, H.F.J.M., Rutte, C.G.: Performance management in healthcare: Performance indicator development, task uncertainty, and types of performance indicators. Soc. Sci. Med. 69, 1523-1530 (2009).

21. Jacobs, M.A.: Complexity: Toward an empirical measure. Technovation. 33, 111-118 (2013).

22. Burton, R.M., DeSanctis, G., Obel, B.: Organizational design a step-by-step approach. Cambridge Univ. Press, Cambridge, MA, USA (2006).

23. Zegers, M., de Bruijne, M.C., Spreeuwenberg, P., Wagner, C., Groenewegen, P.P., van der Wal, G.: Quality of patient record keeping: an indicator of the quality of care? BMJ Qual. Saf. 20, 314-318 (2011).

24. Harper, P.R.: A framework for operational modelling of hospital resources. Health Care Manag. Sci. 5, 165-173 (2002). 